\title{
Genetic and Functional Characterization of the Rice Bacterial Blight Disease Resistance Gene $x a 5$
}

\author{
A. S. Iyer-Pascuzzi, H. Jiang, L. Huang, and S. R. McCouch
}

Department of Plant Breeding and Genetics, Cornell University, Ithaca, NY 14853.

Current address of first author: Department of Biology, Duke University, Durham, NC 27708.

Accepted for publication 5 October 2007.

\section{ABSTRACT}

Iyer-Pascuzzi, A. S., Jiang, H., Huang, L., and McCouch, S. R. 2008. Genetic and functional characterization of the rice bacterial blight disease resistance gene xa5. Phytopathology 98:289-295.

Xanthomonas oryzae pv. oryzae is the causal agent of rice bacterial blight, a destructive rice disease worldwide. The gene $x a 5$ provides racespecific resistance to $X$. oryzae pv. oryzae, and encodes the small subunit of transcription factor IIA. How $x a 5$ functions in bacterial blight resistance is not well understood, and its recessive gene action is disputed. Here we show that $x a 5$ is inherited in a completely recessive manner and the susceptible allele Xa5 is fully dominant. In accordance with this, bacterial growth in heterozygous and homozygous susceptible lines is not significantly different. Further, one allele of Xa5 is sufficient to promote disease in previously resistant plants; additional copies are not predictive of increased lesion length. Surprisingly, a resistant nearly isogenic line (NIL) of an indica variety sustains high levels of bacterial populations compared to the susceptible NIL, yet the resistant plants restrict symptom expression. In contrast, in japonica NILs, bacterial population dynamics differ in resistant and susceptible genotypes. However, both resistant indica and japonica plants delay bacterial movement down the leaf. These results support a model in which $x a 5$-mediated recessive resistance is the result of restricted bacterial movement, but not restricted multiplication.

Additional keywords: Oryza sativa.
Bacterial blight (BB) of rice, caused by Xanthomonas oryzae pv. oryzae is a destructive rice disease in South and Southeast Asia (17). As in other plant-pathogen systems, resistance is conditioned by plant $\mathrm{R}$ (resistance) proteins that recognize corresponding effector proteins from the invading pathogen; lack of recognition results in disease. In rice, resistance to a range of $X$. oryzae pv. oryzae strains is mediated by at least 27 different $X a$ genes. Six Xa genes (Xa21, Xa1, Xa26, Xa5, Xa27, and Xa13) have been cloned $(410,12,27,29,37)$ and the molecular mechanisms behind their function are currently under investigation.

The rice $\mathrm{BB}$ resistance gene $x a 5$ encodes the small subunit of transcription factor IIA (TFIIA $\gamma)(12,14)$. This recessive gene provides race-specific resistance to $X$. oryzae pv. oryzae, and is structurally unlike the more than 40 plant $\mathrm{R}$ genes previously cloned. Of these, only three nonviral R genes, barley mlo, Arabidopsis $R R S 1-R$, and the recently cloned rice $x a 13$, are recessive $(3,4,5)$. In contrast to $x a 5$, both mlo and $R R S 1-R$ provide broadspectrum immunity to their respective pathogens, Blumeria graminis f. sp. hordei (3), and Ralstonia solanacearum (5). In addition, mlo, RRS1-R, and xal3 are structurally unlike xa5. Barley mlo encodes a unique $60 \mathrm{kd} 7$-transmembrane protein with a calmodulin-binding domain (22). RRS1-R is an unusual member of the toll-interleukin nucleotide binding site leucine rich repeat (TIR-NBS-LRR) class of resistance proteins and contains a WRKY transcription domain (5), while xal3 is a unique plasma membrane bound rice protein necessary for pollen development (4).

Our long-term goal is to understand the molecular mechanism(s) of $x a 5$ resistance. Necessary for this understanding is a detailed knowledge of the rice plant's xa5-mediated response to

Corresponding author: S. McCouch; E-mail address: srm4@ cornell.edu

* The $\boldsymbol{e}$-Xtra logo stands for "electronic extra" and indicates that Figures 3 and 4 appear in color online.

doi:10.1094/PHYTO-98-3-0289

(C) 2008 The American Phytopathological Society
$X$. oryzae pv. oryzae, including the gene action of $x a 5$, bacterial population dynamics within rice leaves, and the effect of genetic background. Although initially characterized genetically as a recessive gene (21), conflicting reports have put the genetic inheritance of $x a 5$ in question. Li et al. (16) observed that xa5 functioned additively, and thus was not truly recessive. In contrast, Blair et al. (2) noted that there was no significant difference in lesion length between plants homozygous and heterozygous for Xa5, suggesting that $x a 5$ was completely recessive. One of our objectives was to clarify this question.

While there are a plethora of studies examining bacterial dynamics within the rice-Xanthomonas interaction, these encompass a variety of cultivars containing various resistance genes, some with and some without $x a 5(1,18,23,24)$. Not only are results from such studies often conflicting, but they cannot be directly attributed to $x a 5$ processes. Thus to better understand resistance mediated by $x a 5$, another of our aims was to conduct an analysis of bacterial population growth and movement in isolines containing $x a 5$ (or Xa5), thus ensuring our responses were specific to the $x a 5-X$. oryzae pv. oryzae pathosystem.

In addition to clarifying the gene action of $x a 5$ and bacterial population dynamics within the leaf, our aims were to examine the effects of genetic background in this resistance and to develop a working model of $x a 5$ resistance. We show that the $x a 5$ allele is completely recessive in our indica and japonica isolines, and that one copy of the dominant susceptible allele Xa5 is sufficient for full development of disease. Surprisingly, we find that bacterial populations multiply to high levels in a resistant indica isoline but that bacterial movement down the leaf is restricted. In light of these results, we present a new model for $x a 5$ function.

\section{MATERIALS AND METHODS}

Plant materials and Xanthomonas inoculation. Heterozygous $\mathrm{F}_{2}$ individuals derived from a cross between the resistant and susceptible NILs IRBB5 and IR24, respectively (21), were used 
for the dose-dependency assay. Simple sequence repeat (SSR) markers RM601 and RM611 flanking $x a 5$ (12) and CAPS marker $x a 5-4 \mathrm{~F} / 4 \mathrm{R}$, which detects the functional nucleotide polymorphism between $x a 5$ and $X a 5$ (13), were used to ensure that $F_{2}$ individuals were heterozygous and to verify the genotype of resistant and susceptible isolines. CAPS marker analysis was performed as described (13), except the primer annealing temperature was changed from 53 to $55^{\circ} \mathrm{C}$. Japonica NILs IRBB105 (resistant) and Toyonishiki (susceptible) were used for the transformation work.

Xanthomonas sp. was grown on nutrient agar or WFP media as described (12). The same race, PXO86, was used throughout the study. Plants were clip-inoculated according to the method of Kauffman et al. (15) at an $\mathrm{OD}_{600}=1$, equal to approximately $10^{9} \mathrm{CFU} / \mathrm{ml}$. All inoculations were done in a controlled growth chamber environment at 28 to $30^{\circ} \mathrm{C}$ and 12-h day length. Plants were scored for lesion length 14 days postinoculation (dpi).

Bacterial population and movement assays. Two to five whole leaves of each genotype, per timepoint, were surface sterilized in $95 \%$ ethanol for $10 \mathrm{~s}$ (18), followed by submersion in sterile water for $30 \mathrm{~s}$. Leaves were cut into approximately 1 to $2 \mathrm{~cm}$ pieces, and shaken in 2 to $2.5 \mathrm{ml}$ of $10 \mathrm{mM} \mathrm{MgCl}_{2}$ for $1 \mathrm{~h}$ at room temperature (32), followed by dilution plating, and incubation at $30^{\circ} \mathrm{C}$ for 3 to 4 days.

The same treatment was used for whole leaves in the bacterial movement assays. The top $12 \mathrm{~cm}$ of each leaf below the point of inoculation was cut into four, $3 \mathrm{~cm}$ pieces. Each $3 \mathrm{~cm}$ piece was cut into approximately $1 \mathrm{~cm}$ pieces, shaken in $1 \mathrm{ml}$ of $10 \mathrm{mM}$ $\mathrm{MgCl}_{2}$ for $1 \mathrm{~h}$, dilution plated, and incubated at $30^{\circ} \mathrm{C}$. Scissors were disinfected between each cut for leaf sections and after each leaf for whole leaf assays.

Calculation of area under disease progress curve (AUDPC). The AUDPC was calculated according to Shaner and Finney (26): $\Sigma\left[\left(x_{i+1}+x_{i}\right) / 2\right]\left[t_{i+1}-t\right]$, where $x=$ average log CFU and $t=$ evaluation date. AUPDC for IRBB5 was divided by that of IR24 to estimate the relative AUPDC.

Plasmid construction. DNA isolated from bacterial artificial chromosome (BAC) clone AF532975 containing the Xa5 gene from IR24 was digested with HindIII, and a 9,862-bp fragment containing only the small subunit of TFIIA genomic DNA and $3 \mathrm{~kb}$ upstream native promoter was subcloned into a pCAMBIA1300 vector. The constructs containing the TFIIA $\gamma$ fragment and the empty pCAMBIA1300 vector were then introduced into Agrobacterium tumefaciens LBA4404 by electroporation. The transformed Agrobacteria were used for rice transformation.

Rice transformation. Mature seeds were dehulled and surfacesterilized in $70 \%$ ethanol for $30 \mathrm{~s}$, shaken in $3.0 \%$ sodium hypochlorite $(50 \%$, vol/vol, Clorox) for $20 \mathrm{~min}$, and then rinsed with sterile water three times. The seeds were then placed on the calli induction medium containing Murashige and Skoog (MS) basic (Caisson laboratories, Inc., Rexburg, ID), 2,4-dichlorophenoxyacetic acid $2.5 \mathrm{mg} /$ liter, 6-benzylaminopurine $0.2 \mathrm{mg} / \mathrm{liter}$, casine hydrolysate $0.3 \mathrm{~g} / \mathrm{liter}$, proline $0.3 \mathrm{~g} / \mathrm{liter}$, maltose $30 \mathrm{~g} / \mathrm{liter}$, and phytagel $3.0 \mathrm{~g} /$ liter, pH 5.8 .

TABLE 1. Plant material discussed in this study

\begin{tabular}{lcccc}
\hline & $\begin{array}{c}\text { Abbreviation in } \\
\text { text }\end{array}$ & Genotype & Phenotype & $\begin{array}{c}\text { O. sativa } \\
\text { subpopulation }\end{array}$ \\
\hline IRBB5 & $I R$ & $x a 5 x a 5$ & $\mathrm{R}^{\mathrm{a}}$ & indica \\
IR24 & $I S$ & Xa5Xa5 & $\mathrm{S}^{\mathrm{b}}$ & indica \\
IRBB105 & $J R$ & $x a 5 x a 5$ & $\mathrm{R}$ & japonica \\
Toyonishiki & $J S$ & Xa5Xa5 & $\mathrm{S}$ & japonica \\
DZ192 & & $x a 5 x a 5$ & $\mathrm{R}$ & aus \\
IR1545-339 & & $x a 5 x a 5$ & $\mathrm{R}$ & aus/indica \\
\hline
\end{tabular}

${ }^{a}$ Resistant.

b Susceptible.

${ }^{c}$ DZ192 is the source of $x a 5$ for both $I R$ and $J R$.
Calli infiltration, co-cultivation and selection were carried out as described previously (6). After growing on the selection medium for 14 to 20 days, the calli were transferred to a preregeneration medium, containing MS basic, 6-benzylaminopurine $2 \mathrm{mg} / \mathrm{liter}$, 1-naphthaleneacetic acid $1 \mathrm{mg} / \mathrm{liter}$, abscisic acid $5 \mathrm{mg} /$ liter, maltose $20 \mathrm{mg} /$ liter, L-proline $500 \mathrm{mg} /$ liter, glutamine $500 \mathrm{mg} / \mathrm{liter}$, casine hydrolysate $300 \mathrm{mg} / \mathrm{liter}$, phytagel $3 \mathrm{~g} / \mathrm{liter}$, hygromycin $50 \mathrm{mg} / \mathrm{liter}$, and cefotaxime $250 \mathrm{mg} / \mathrm{liter}, \mathrm{pH} 5.8$. The calli were kept in the dark at $28^{\circ} \mathrm{C}$ for 2 weeks, followed by two cycles of regeneration. The regeneration medium contained MS basic, 1-naphthaleneacetic acid $0.25 \mathrm{mg} / \mathrm{liter}$, kinetin $2.5 \mathrm{mg} / \mathrm{liter}$, maltose $20 \mathrm{~g} / \mathrm{liter}$, and phytagel $3 \mathrm{~g} / \mathrm{liter}, \mathrm{pH} 5.8$, supplemented with hygromycin $50 \mathrm{mg} / \mathrm{liter}$ and cefotaxime $250 \mathrm{mg} / \mathrm{liter}$. During the second cycle of regeneration, cefotaxime was eliminated from the medium. The calli were grown at $28^{\circ} \mathrm{C}$ and under $14 / 10 \mathrm{~h} \mathrm{light/}$ dark photoperiods. The regenerating shoots were then transferred onto rooting medium containing MS basic, maltose $20 \mathrm{mg} / \mathrm{liter}$, phytagel $3 \mathrm{~g} /$ liter, $\mathrm{pH} 5.8$, for another 2 weeks under the same photoperiods. After 10 to 14 days on rooting medium, the plantlets were grown in tap water for 7 days in growth chamber before transferring them to soil under greenhouse conditions as described previously (6).

\section{RESULTS}

The $\mathrm{Xa5}$ allele is not dose-dependent in the indica IR24. In the $X$. oryzae pv. oryzae-rice pathosystem, lesions are typically measured at $14 \mathrm{dpi}$. Under our conditions, we observe that plants with lesions less than $4 \mathrm{~cm}$ are resistant, while those greater than $4 \mathrm{~cm}$ are susceptible. To examine the dose-dependency of $\mathrm{Xa5}$, we used the pair of indica near isogenic lines (NILs) IRBB5 (xa5xa5, resistant) and IR24 (Xa5Xa5, susceptible). IR24 does not contain any documented resistance genes to Philippine races of $X$. oryzae pv. oryzae (PXO). IRBB5 contains IR24 sequence throughout most of the genome, but has an introgression with $x a 5$ on chromosome 5 (Table 1). For clarity, we will refer to the susceptible indica isoline IR24 as $I S$, and the resistant indica isoline IRBB5 as $I R$. Inoculation of these NILs and heterozygous $\mathrm{F}_{2} \mathrm{~S}$ from an $I R \times I S$ cross with $X$. oryzae pv. oryzae strain PXO86 (a race 2 strain, avirulent on $I R$ ) showed no significant difference in lesion length between $I S$ and heterozygous $\mathrm{F}_{2} \mathrm{~s} 14$ dpi (Fig. 1A). In addition, bacterial populations over time in heterozygous plants were similar to those in homozygous susceptible IS individuals, as measured by the AUPDC (26). AUDPC for heterozygotes was more than $99 \%$ that of $I S$ (Fig. 1B). These results demonstrate that the Xa5 allele is not dose-dependent in the indica IR24 background.

$X$. oryzae pv. oryzae populations multiply extensively in resistant indica isolines. Unlike many previous studies done with $x a 5$, which compared responses of $x a 5$ among cultivars containing additional resistance genes, the NILs $I S$ and $I R$ allow characterization of responses which are specific to $x a 5$. Thus to further analyze $x a 5$ or $X a 5$ mediated responses to $X$. oryzae pv. oryzae, we examined bacterial numbers in homozygous susceptible and resistant indica isolines by measuring bacterial titer in whole leaves. Since we had observed that $x a 5$ was completely recessive, we expected to find much smaller populations of bacteria within resistant $I R$ leaves. Plants were inoculated with $10^{9} \mathrm{CFU} / \mathrm{ml}$ of PXO86. The overall AUDPC for $I R$ was unexpectedly high, approximately $90 \%$ that of both $I S$ and heterozygotes (Fig. 1B). Surprisingly, $X$. oryzae pv. oryzae numbers in $I R$ leaves were only about 10 -fold lower than $I S$ or susceptible heterozygotes 2 to 10 days after inoculation. On days 12 to 14, this difference narrowed to less than 10 -fold between resistant and susceptible NILs. This may have been because lesions on susceptible leaves have begun to desiccate by $14 \mathrm{dpi}$, most likely resulting in fewer viable bacterial numbers within the whole leaves of susceptible plants at this timepoint. However, in contrast, resistant IRBB13 
plants expressing the recessive bacterial blight allele xal3 supported more than 100-fold fewer bacteria 6 and 8 dpi and more than 1,500-fold fewer bacteria 10 to $14 \mathrm{dpi}$, than a corresponding transgenic line expressing the susceptible allele Xa13 (4). Importantly, although $X$. oryzae pv. oryzae multiplied extensively in resistant $I R$ lines, lesion lengths were consistently less than $4 \mathrm{~cm}$ (Fig. 1A).

Genetic background affects bacterial multiplication in rice leaves. The bacterial population dynamics results were not only surprising but diverged from other published studies that examined resistant responses in different cultivars containing xa5. We postulated that one reason for this might be due to differences in rice genetic backgrounds, or the epistatic interactions among specific alleles in one cultivar. Rice is rich in allelic diversity, and this is partitioned into distinct subpopulations, including the welldifferentiated indica and japonica groups $(8,9,20)$. Resistance to $X$. oryzae pv. oryzae, such as that mediated by Xa26 or Xa21, is known to vary among different rice cultivars and transgenics, as measured by lesion length $(27,29,33)$, suggesting that genetic background may play a role in resistance mediated by specific $\mathrm{Xa}$ genes.

To test our hypothesis, we examined final bacterial numbers and lesion lengths in a japonica background 14 dpi and compared these to our results in an indica genetic background. We examined $X$. oryzae pv. oryzae population growth 14 dpi because we consistently measure final lesion lengths and disease progress at this timepoint. We used existing japonica NILs, i.e., the susceptible Toyonishiki (Xa5Xa5) and the resistant IRBB105 (xa5xa5) (Table 1) (21). For clarity, we will use the terms $J S$ and $J R$ to refer to the susceptible japonica isoline Toyonishiki and the resistant japonica isoline IRBB105, respectively (Table 1). Like the indica NILs, these varieties are nearly identical with the exception of an introgression containing $x a 5$ in the sub-telomeric region of chromosome 5. In contrast to the indica NILs described above, we observed an approximately 50-fold difference in X. oryzae pv. oryzae population growth in whole leaves of 8 -week-old plants between $J S$ and its resistant NIL $J R$ at day 14 while lesion lengths were correspondingly distinct (Fig. 2A). Though bacterial numbers were not entirely suppressed in $J R$, the japonica subpopulation appeared to be more resistant to PXO86 X. oryzae pv. oryzae than the indica, as resistant japonica plants had smaller lesion lengths and lower overall bacterial populations 14 dpi (Fig. $1 \mathrm{~B}$ and $2 \mathrm{~A}$ and $\mathrm{B}$ ) compared with their indica counterparts. Thus, $X$. oryzae pv. oryzae-xa5 dynamics appear to differ in the indica and japonica NILs.

Bacterial movement is restricted in both indica and japonica resistant plants. Since resistant plants support large numbers of bacteria, yet maintain small lesion lengths, we questioned how $X$. oryzae pv. oryzae-infected resistant rice plants maintain small lesion lengths. We hypothesized that bacterial movement within resistant and susceptible leaves was dissimilar. Bacterial movement throughout the rice leaf in both indica and japonica NILs was analyzed at 3, 7, 9, and 13 days post-clip inoculation in 8 -week-old plants. The top $12 \mathrm{~cm}$ of each leaf was cut into four 3-cm subsections, and labeled A, B, C, and D, with A being the point of inoculation (Fig. 3).

In both indica and japonica NILs, X. oryzae pv. oryzae movement down the leaf was dramatically faster in susceptible than in resistant leaves. Movement in resistant leaves appeared to be more restricted in $J R$ than $I R$ (Fig. $3 \mathrm{~A}$ to $\mathrm{D}$ ). Three days after inoculation $X$. oryzae pv. oryzae growth and movement in resistant and susceptible plants was not significantly different in any of the four sections in either indica or japonica NILs. X. oryzae pv. oryzae were concentrated in the first $3 \mathrm{~cm}$ after the point of inoculation, but were beginning to move past that point into section B. By day 7, bacteria in both indica and japonica susceptible NILs had moved more than $9 \mathrm{~cm}$ into section D. By day 7, bacteria in $I R$ had reached section $\mathrm{C}$, while those in $J R$ were restricted to section B. By days 9 and 13, levels of $X$. oryzae pv. oryzae populations were high in sections $\mathrm{C}$ and $\mathrm{D}$ in both susceptible NILs, but severely restricted in both resistant NILs. This was particularly apparent more than $9 \mathrm{~cm}$ from the point of inocula-
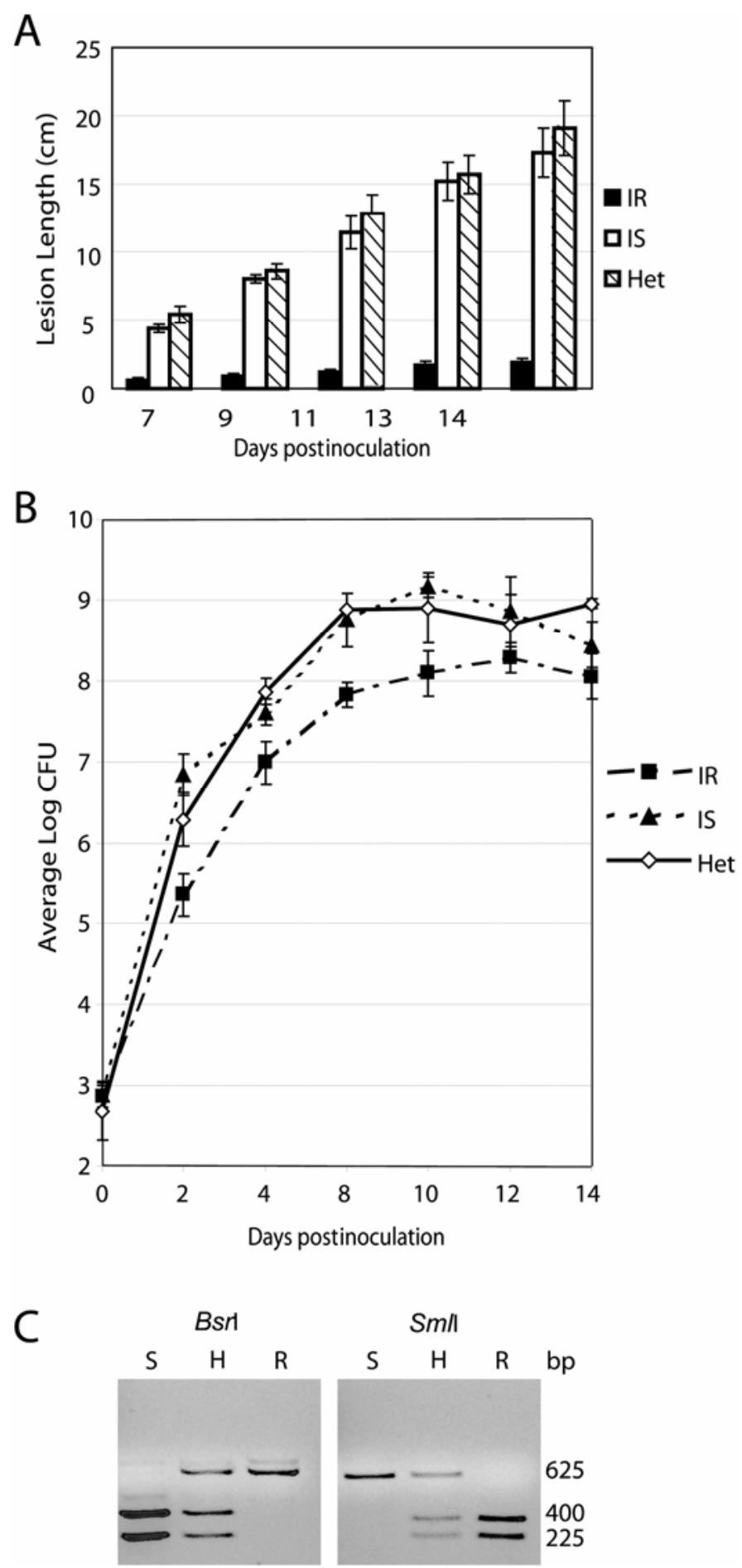

Fig. 1. A, Lesion lengths on homozygous susceptible and heterozygous susceptible 8-week-old indica plants are not significantly different. $I R=$ IRBB5, the resistant indica NIL; IS = IR24, the susceptible indica NIL. Measurements are 14 days postinoculation. B, Bacterial population growth in $I R, I S$, and heterozygotes. Eight-week-old plants were inoculated with approximately $10^{9}$ CFU/ml PXO86. The AUDPC values were 98.8, 110.2, and 109.6 for $I R, I S$, and heterozygotes, respectively. C, Genotypic analysis of $I R, I S$, and heterozygote plants using CAPS marker $x a 5-4 \mathrm{~F} / 4 \mathrm{R}$ and the restriction enzymes BsrI and SmlI (13). BsrI cuts the susceptible allele; SmlI cuts the resistant. Experiment was repeated three times with three to five leaves per genotype per timepoint; similar results were obtained each time. Representative results are shown; error bars indicate standard error. 
tion, in section D. In section A at day 13, both susceptible NILs supported lower levels of bacteria than their resistant counterparts. Again, this may be due to the desiccation of lesions in susceptible leaves at these days, resulting in fewer numbers of viable bacteria. Interestingly, there were significant numbers of bacteria in both $I R$ and $J R$ plants in section B (3 to $6 \mathrm{~cm}$ ) at day 9 and day 13 , yet lesions do not typically extend this far down the leaf in 8-week-old plants, even 14 dpi (Fig. 1 and 2A).

Genetic background does not affect inheritance of $x a 5$. Because of the observed differences in bacterial growth in japonica and indica varieties, we hypothesized that there were also differences in the inheritance of $x a 5$ in the two subspecies. Rather than create another F2 population from a cross of susceptible by resistant japonica isolines, we developed japonica transgenic Xa5 plants to test this hypothesis, as these allowed us to test an additional hypothesis regarding $\mathrm{Xa} 5$ dosage. Our dose-dependency results above indicated that one copy of Xa5 was sufficient for disease in a heterozygous plant. However, we wanted to further examine this to understand whether $X a 5$ was able to cause disease in a formerly resistant $x a 5 x a 5$ genotype, suggesting that it may be a 'susceptibility allele'. Thus our transgenic plants allowed us to test two different hypotheses: (i) that genetic background affects the inheritance of $x a 5$, and (ii) that one allele of Xa5 is sufficient for disease, even in plants with two copies of the recessive resistance allele.

For our transformation, we chose to use the japonica isolines Toyonishiki (susceptible) and IRBB105 (resistant). We used a fragment of IS DNA containing Xa5 and $3 \mathrm{~kb}$ upstream to transform $J S$ and $J R$ using Agrobacterium and hygromycin selection. Transformation with the empty vector was used as a control. Rice

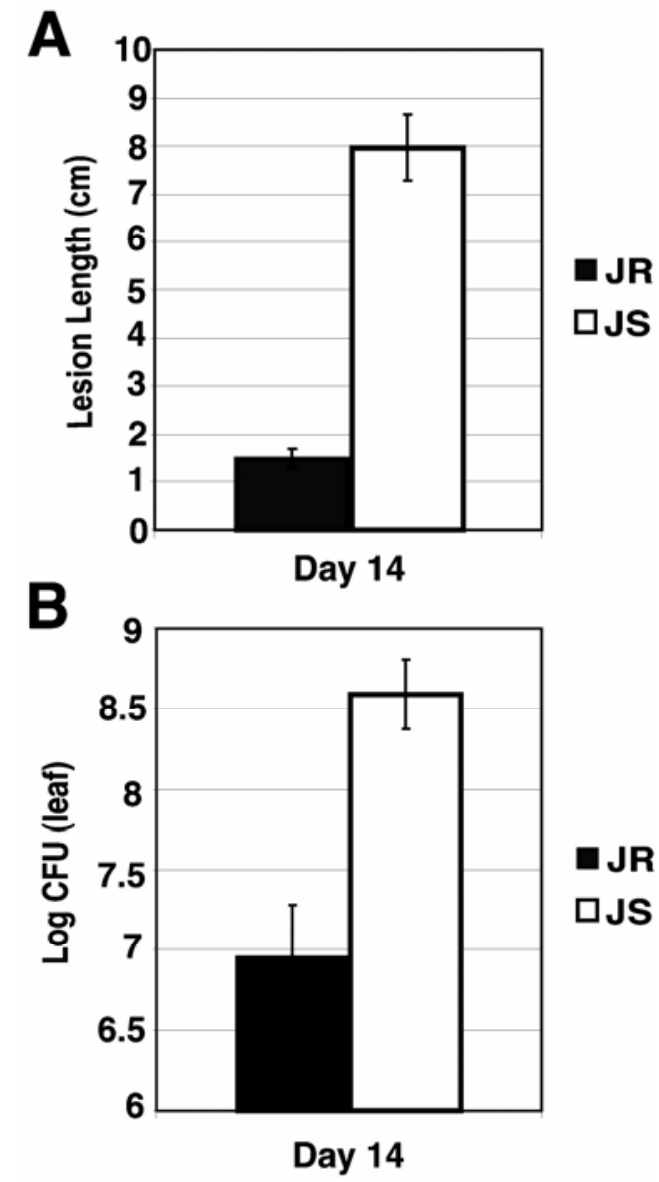

Fig. 2. A, Lesion lengths of 8 -week-old $J R$ and $J S 14$ days postinoculation (dpi) and B, bacterial growth on 8-week-old $J R$ and $J S$ plants 14 dpi. Experiment was repeated twice with five to six leaves per genotype. Representative results are shown. Error bars indicate standard error. varieties vary widely in their regeneration and transformation capacities, and transformation of $J S$ and $J R$ proved difficult, with approximately 4.1 and $4.6 \%$ efficiency, respectively. Seventeen T0 JR (xa5xa5/Xa5-) independent transformants, 15 JS (Xa5Xa5/ $X a 5$-), three $J R$ empty vector, and $12 J S$ empty vector controls were generated. To confirm transformation, the Xa5 transgene was amplified from each T0 plant using primers specific to the hygromycin gene and the right border of the vector. Transgene
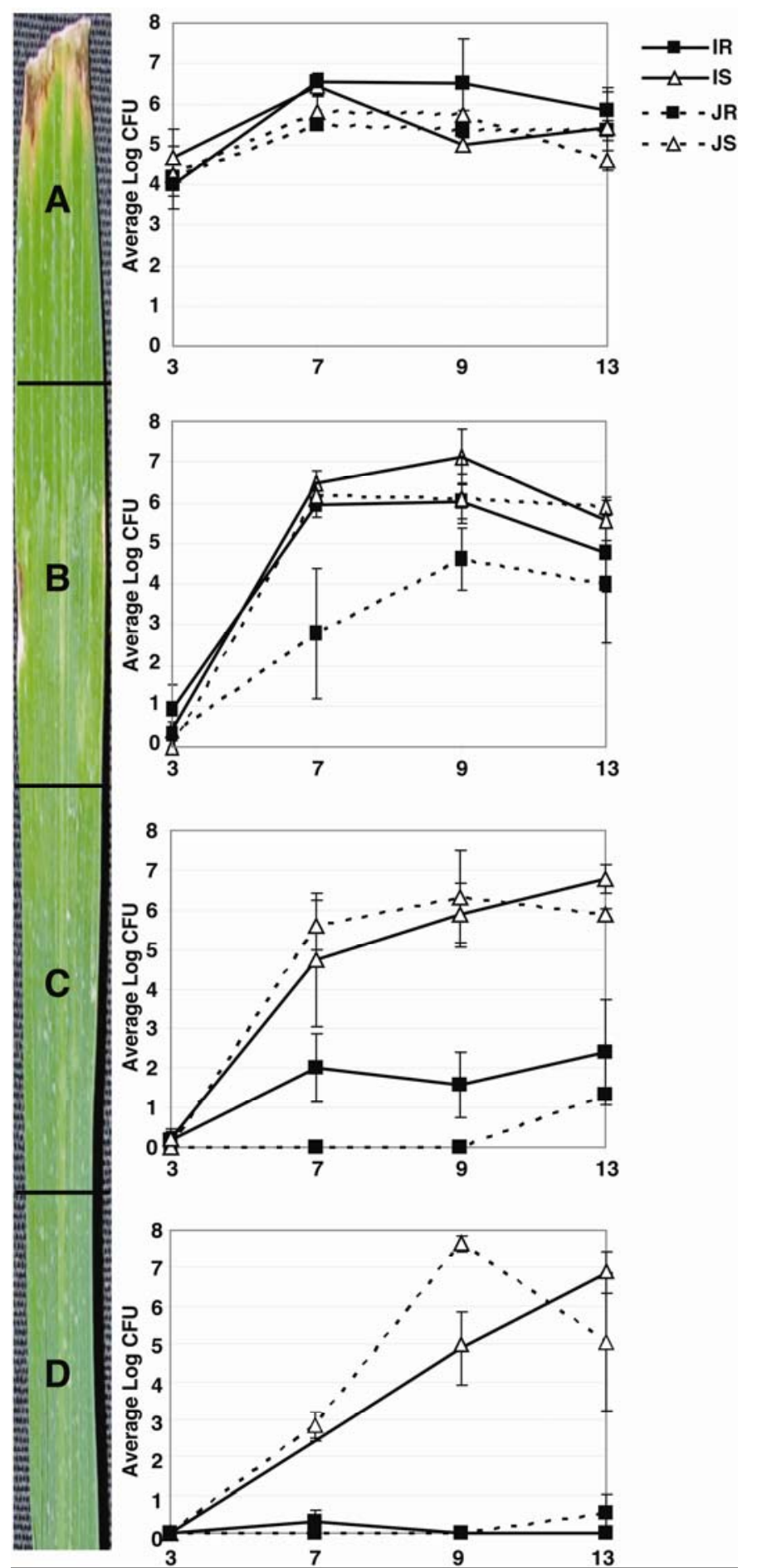

Fig. 3. Bacterial growth in 8-week-old $I R$ (solid squares, solid lines), IS (open triangles, solid lines), $J R$ (solid squares, dashed lines), and $J S$ (open triangles, dashed lines) in section $\mathbf{A}, \mathbf{B}, \mathbf{C}$, and $\mathbf{D}$ of the rice leaf, at 3, 7, 9, and 13 days postinoculation. Each section is $3 \mathrm{~cm}$. Experiment was repeated three times, with two to five leaves per genotype per timepoint. Similar results were obtained each time; representative results are shown. Error bars indicate standard error (not shown if smaller than the symbols). 
copy number was confirmed with DNA blot analysis (data not shown).

To test our hypotheses, we selfed T0 plants and inoculated 10 8-week-old individuals of T1 families with PXO86 of X. oryzae pv. oryzae. The transgene was amplified from each member of every family prior to inoculation with primers described above (Fig. 4C). When we inoculated both transgene (+) and transgene (-) siblings, susceptibility cosegregated with the transgene (Fig. 4B). Five independent single copy $J R:: X a 5$ transgenic families with an average lesion length of $7.9 \pm 0.8 \mathrm{~cm}$, segregated $3: 1$ for susceptibility (data not shown; Fig. 4 and Table 2). Untransformed control susceptible $J S$ plants had an average lesion length of $8.0 \pm 0.7 \mathrm{~cm}$ while untransformed resistant $J R$ average lesion length was $1.5 \pm 0.2 \mathrm{~cm}$. The $J R: X a 5$ transgenics therefore had similar lesion lengths to the untransformed susceptible parent. Thus no significant difference between untransformed susceptible japonicas $(J S)$ and Xa5 transformed previously resistant japonicas $(J R:: X a 5)$ was observed. We therefore conclude that, in the japonica subspecies as in the indica, $x a 5$ operates as a recessive gene and genetic background does not affect its gene action.

A

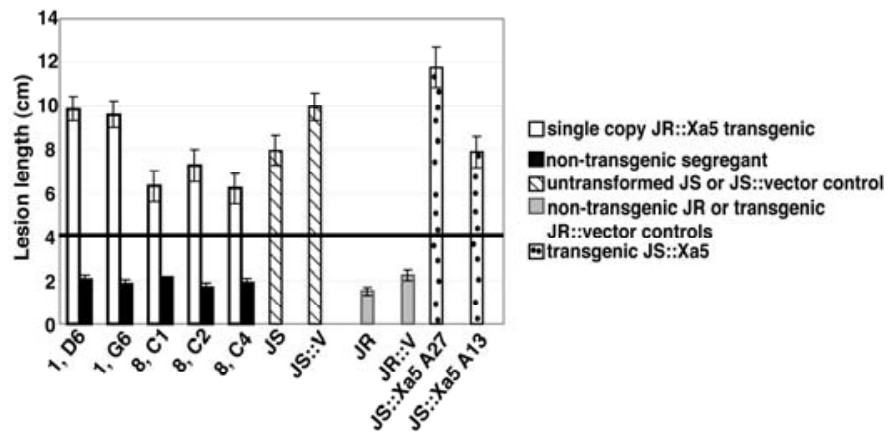

B

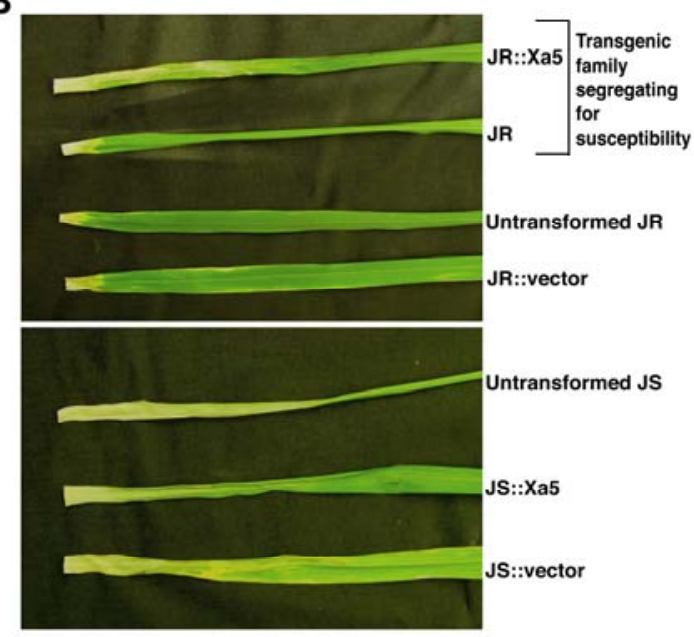

C

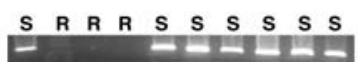

Fig. 4. A, Lesion lengths of five independent single-copy Xa5 transformant families and transgenic control lines. 1,D6 - 8,C4 = single copy $J R:: X a 5$ independent transgenic families; $J S=$ susceptible untransformed japonica $\mathrm{NIL}$ $(X a 5 X a 5) ; J S:: \mathrm{V}=J S$ transformed with empty vector; $J R=$ resistant untransformed japonica NIL (xa5xa5), JR::V = JR transformed with empty vector, $J S:: X a 5$ A27 and A13 = independent transformants of $J S$ transformed with $X a 5$. Black line indicates the boundary below which plants are resistant under our conditions ( $<4 \mathrm{~cm}$ lesion length). B, Lesion lengths of transgenic families and controls. C, Polymerase chain reaction (PCR) amplification of the right border of pCAMBIA::Xa5 showing segregation of susceptibility with the transgene. All measurements were taken on approximately 8-week-old plants 14 days postinoculation.
Additional insertions of $\mathrm{Xa5}$ do not result in increased disease severity in previously resistant genotypes. Since the transgenic $J R:: X a 5$ plants also contain two copies of the recessive resistant xa5 allele, our results show that one allele of Xa5 is sufficient for disease even in plants with two copies of $x a 5$. Moreover, insertion of more than one copy of $\mathrm{Xa5}$ was not predictive of longer lesions (Table 2), indicating that additional copies of Xa5 were not sufficient to induce greater disease symptoms in these plants. These results corroborate our dose-dependency results and suggest that $\mathrm{X} a 5$ may be a susceptibility allele.

\section{DISCUSSION}

We have shown that in the rice $X$. oryzae pv. oryzae system, one allele of $X a 5$ is necessary and sufficient for susceptibility to a race 2 strain of $X$. oryzae pv. oryzae, even when two copies of the resistant alleles are present. In contrast to $\mathrm{Li}$ et al. (16), but in agreement with Blair et al. (2), we demonstrated that $x a 5$ is completely recessive in our indica and japonica NILs. The conflicting results may be the result of differences in inoculum concentration or environmental conditions, as disease development is known to vary in response to temperature (17) and initial inoculum concentration (25). Indeed, initial observations from our lab (12) suggested that F1 heterozygotes have a highly variable, intermediate lesion length. However, three subsequent experiments under controlled environmental conditions found no difference in lesion length among Xa5xa5 heterozygotes.

Our results indicate that there is a difference in bacterial growth in NILs of disparate genetic backgrounds. This difference in genetic background could be responsible for the contradictory results regarding bacterial population dynamics observed by several different workers in the field $(1,18,23,24)$. Of the preceding studies, only Barton-Willis and colleagues used a cultivar containing $x a 5$. In contrast to our work, these authors observed lower levels of bacterial multiplication in cultivar IR1545-339 (Table 1), containing the $x a 5$ gene. However, IR1545-339 contains DNA from the Aus cultivar, DZ192, the original donor of xa5 (21). DZ192 may contain additional major genes or quantitative trait loci (QTL) for bacterial blight, which, if present in IR1545-339, could alter the defense response and explain differences between our results and theirs. Interestingly, Barton-Willis and colleagues also observed delayed bacterial movement in resistant and susceptible varieties. Taken with our results regarding $X$. oryzae pv. oryzae population growth in leaves of indica and japonica cultivars, this suggests that the deciding factor in $x a 5$-mediated

TABLE 2. Lesion lengths of independent $X a 5$ transgenic families

\begin{tabular}{lcc}
\hline Family & $\begin{array}{c}\text { Average lesion length }{ }^{\mathrm{a}}(\mathrm{cm}) \\
\pm \mathrm{SE}\end{array}$ & $\begin{array}{c}\text { Transgene copy } \\
\text { number }\end{array}$ \\
\hline$J R:: X a 5^{\mathrm{b}}$ & $9.9 \pm 0.6$ & 1 \\
$1, \mathrm{D} 6$ & $9.6 \pm 0.6$ & 1 \\
$1, \mathrm{G} 6$ & $7.4 \pm 0.9$ & 2 \\
$1, \mathrm{E} 8$ & $9.7 \pm 0.5$ & 2 \\
$2, \mathrm{~B} 8$ & $6.3 \pm 0.7$ & 1 \\
$8, \mathrm{C} 1$ & $7.3 \pm 0.8$ & 1 \\
$8, \mathrm{C} 2$ & $6.2 \pm 0.7$ & 1 \\
$8, \mathrm{C} 4$ & $7.3 \pm 0.7$ & 2 \\
$8, \mathrm{C} 3$ & & 3 \\
$J S:: X a 5^{\mathrm{c}}$ & $7.9 \pm 0.7$ & 2 \\
A13 & $11.8 \pm 0.9$ & \\
A27 & & Multiple \\
Controls & $2.2 \pm 0.2$ & 2 \\
$J R::$ Vector & $10.0 \pm 0.6$ & 0 \\
$J S::$ Vector & $1.5 \pm 0.2$ & 0 \\
$J R$ untransfomed & $8.0 \pm 0.7$ & \\
$J S$ untransformed & & \\
\hline
\end{tabular}

a Average of seven leaves.

b $J R=$ resistant japonica IRBB 105 .

c $J S=$ susceptible japonica Toyonishiki. 
resistance is not the amount of bacterial multiplication within the rice leaf, but rather the ability of $X$. oryzae pv. oryzae to move within the leaf.

Jiang et al. (14) recently proposed a mechanism for xa5 resistance in which the protein is able to bind to a positive transcriptional activator, thereby activating specific genes, while the susceptible protein may have stronger affinity for a transcriptional repressor that could silence genes. They suggest that the variability in F1 lesion lengths observed by $\mathrm{Li}$ et al. (16) may be due to competition between resistant and susceptible proteins for the activator and repressor. However, in light of our results, we suggest a different model.

We propose that Xa5 may be a nuclear target of Xanthomonas spp. that interacts with one or more $X$. oryzae pv. oryzae effectors. A major class of $X$. oryzae pv. oryzae effectors is comprised of members of the AvrBs3 family. Members of this family have nuclear localization signals and other features of eukaryotic transcription factors (11), and play roles both in promoting disease and triggering defense $(30,35,36,39)$. Additionally, members of this family were shown to suppress activation of $P R$ genes (7). Interaction of such an effector with $\mathrm{Xa} 5$ may promote plant disease. Since one allele of $\mathrm{Xa} 5$ is sufficient for disease in previously resistant plants, susceptibility appears to be an active process. Thus disease may occur through the activation of host genes important for bacterial fitness, virulence or movement within the plant. Such genes could include those involved in sugar, iron, or nitrogen metabolism, or those implicated in cell permeability. Indeed, $O s 8 N 3$, encoding an integral membrane protein, was recently identified as a bacterial blight susceptibility factor (34). Since the resistant allele product xa5 differs from the susceptible by only one amino acid (12), we postulate that the resistant protein cannot prevent the activation of the disease-promoting genes either because there is no interaction between an $X$. oryzae pv. oryzae effector and $x a 5$, or because such an interaction is nonproductive.

How then does resistance develop in an xa5xa5 plant? We propose that this resistance may be due to preformed secondary defenses, and/or induced basal defenses. Although similar in nature to that induced by $\mathrm{R}$ genes, basal defense responses may be weaker and later, and may allow high levels of pathogen growth $(19,28,31)$. We hypothesize that such defenses could delay bacterial movement down the leaf as well as prevent symptom expression, but may not be able to seriously attenuate bacterial multiplication in resistant lines. In a heterozygote, these defenses would be overcome by Xa5-X. oryzae pv. oryzae effector activation of disease promoting genes. Smaller bacterial populations in our resistant japonica isoline may be due to additional defense genes within this variety. A model in which $x a 5$ mediated resistance is due to basal defenses that delay bacterial movement, but not multiplication, could explain why IRBB5 ( $x a 5 x a 5$ ) plants are able to maintain resistance, even though they allow high levels of bacterial multiplication. Further, if $x a 5$ promoted secondary, and not $\mathrm{R}$ gene mediated defenses, we might expect to see variable lesion lengths on resistant plants. Indeed, lesion lengths on resistant indica and japonica plants have been reported to vary from less than $1 \mathrm{~cm}$ to $5 \mathrm{~cm}$ (data not shown) (38). Finally, xa5 mediated resistance to the avirulent strain PXO86 does not produce a typical $24 \mathrm{~h}$ hypersensitive reaction (HR) commonly observed in $\mathrm{R}$ gene mediated responses. Instead, a delayed and somewhat weak HR becomes apparent 48 to $72 \mathrm{~h}$ after infiltration of the pathogen (A. J. Bogdanove, personal communication). All of these observations are unexpected if $x a 5$ were responsible for $\mathrm{R}$ gene related defenses.

In conclusion, $x a 5$ is a completely recessive gene that mediates resistance in part through the restriction of bacterial movement. The dominant allele $\mathrm{Xa5}$ is necessary and sufficient for susceptibility. It will be interesting to distinguish whether the restriction of bacterial movement is a general phenomenon of other recessive resistance alleles, particularly those involved in the rice bacterial blight response.

\section{ACKNOWLEDGMENTS}

We thank J. Anderson, A. Bogdanove, J. Leach, H. Nguyen, P. Pascuzzi, and R. Wisser for helpful comments on the manuscript, and L. Swales for help with graphics. This work was supported by USDA NRI grant no. 2003-35301-13130 and USDA National Needs Fellowship in Molecular Plant Pathology 91-38420-6081 to A. S. Iyer-Pascuzzi.

\section{LITERATURE CITED}

1. Barton-Willis, P. A., Roberts, P. D., Guo, A., and Leach, J. E. 1989. Growth dynamics of Xanthomonas campestris pv. oryzae in leaves of rice differential cultivars. Phytopathology 79:573-578.

2. Blair, M. W., Garris, A. J., Iyer, A. S., Chapman, B., Kresovich, S., and McCouch, S. R. 2003. High resolution genetic mapping and candidate gene identification at the xa5 locus for bacterial blight resistance in rice (Oryza sativa L.). Theor. Appl. Genet. 107:62-73.

3. Büschges, R., Hollricher, K., Panstruga, R., Simons, G., Wolter, M., Frijters, A., van Daelen, R., van der Lee, T., Diergaarde, P., Groenendijk, J., Topsch, S., Vos, P., Salamini, F., and Schulze-Lefert, P. 1997. The barley Mlo gene: A novel control element of plant pathogen resistance. Cell 88:695-705.

4. Chu, Z., Yuan, M., Yao, J., Ge, X., Yuan, B., Xu, C., Li, X., Fu, B., Li, Z., Bennetzen, J. L., Zhang, Q., and Wang, S. 2006. Promoter mutations of an essential gene for pollen development result in disease resistance in rice. Gene Dev. 20:1250-1255.

5. Deslandes, L., Olivier, J., Theulieres, F., Hirsch, J., Feng, D. X., BittnerEddy, P., Beynon, J., and Marco, Y. 2002. Resistance to Ralstonia solanacearum in Arabidopsis thaliana is conferred by the recessive $R R S 1-R$ gene, a member of a novel family of resistance genes. Proc. Natl. Acad. Sci. USA 99:2404-2409.

6. Dey, M., Jiang, H., and Wu, R. 2002. Antinecrotic substances improved regeneration frequency of transgenic rice. Rice Genetics Newsl. 19:82-84.

7. Fujikawa, T., Ishihara, H., Leach, J. E., and Tsuyumu, S. 2006. Suppression of defense response in plants by the avrBs3/pthA gene family of Xanthomonas spp. Mol. Plant-Microbe Interact. 19:342-349.

8. Garris, A. J., Tai, T. H., Coburn, J. R., Kresovich, S., and McCouch, S. 2005. Genetic structure and diversity in Oryza sativa L. Genetics 169:1631-1638.

9. Glaszmann, J. C. 1987. Isozymes and classification of Asian rice varieties. Theor. Appl. Genet. 74:21-30.

10. Gu, K., Yang, B., Tian, D., Wu, L., Wang, D., Sreekala, C., Yang, F., Chu, Z., Wang, G. L., White, F. F., and Yin, Z. 2005. $R$ gene expression induced by a type-III effector triggers disease resistance in rice. Nature 435:11221125.

11. Gürlebeck, D., Thieme, F., and Bonas, U. 2006. Type III effector proteins from the plant pathogen Xanthomonas and their role in the interaction with the host plant. J. Plant Physiol. 163:233-255.

12. Iyer, A. S., and McCouch, S. R. 2004. The rice bacterial blight resistance gene $x a 5$ encodes a novel form of disease resistance. Mol. Plant-Microbe Interact. 17:1348-1354.

13. Iyer-Pascuzzi, A. S., and McCouch, S. R. 2006. Functional markers for xa5-mediated resistance in rice (Oryza sativa L.). Mol. Breed. 19:291296.

14. Jiang, G. H., Xia, Z. H., Zhou, Y. L., Wan, J., Li, D. Y., Chen, R. S., Zhai, W. X., and Zhu, L. H. 2006. Testifying the rice bacterial blight resistance gene $x a 5$ by genetic complementation and further analyzing $x a 5$ (Xa5) in comparison with its homolog TFIIAgamma1. Mol. Genet. Genomics 275:354-366.

15. Kauffman, H. E., Reddy, A. P. D., Ksiek, S. P. V., and Marca, S. D. 1973. An improved technique for evaluating resistance of race varieties to Xanthomonas oryzae. Plant Dis. Rep. 57:537-541.

16. Li, Z. K., Sanchez, A., Angeles, E., Singh, S., Domingo, J., Huang, N., and Khush, G. S. 2001. Are the dominant and recessive plant disease resistance genes similar? A case study of rice $R$ genes and Xanthomonas oryzae pv. oryzae races. Genetics 159:757-765.

17. Mew, T. W. 1987. Current status and future prospects of research on bacterial blight of rice. Annu. Rev. Phytopathol. 25:359-382.

18. Mohiuddin, M. S., and Kauffman, H. E. 1975. Multiplication studies of Xanthomonas oryzae isolates on differential rice varieties. Curr. Sci. 44:637-638.

19. Nimchuk, Z., Eulgem, T., Holt, B. F., 3rd, and Dangl, J. L. 2003. Recognition and response in the plant immune system. Annu. Rev. Genet. 37:579-609.

20. Oka, H. I. 1988. Page 254 in: Origin of Cultivated Rice. Scientific Societies Press and Elsevier Science Publishers, Tokyo, Japan. 
21. Ogawa, T., Yamamoto, T., Khush, G. S., Mew, T. W., and Kaku, H. 1988. Near-isogenic lines as international differentials for resistance to bacterial blight of rice. Rice Genetics Newsl. 5:106-109.

22. Panstruga, R., and Schulze-Lefert, P. 2003. Corruption of host seventransmembrane proteins by pathogenic microbes: A common theme in animals and plants? Microbes Infect. 5:429-437

23. Parry, R. W. H., and Callow, J. A. 1986. The dynamics of homologous and heterologous interactions between rice and strains of Xanthomonas campestris. Plant Pathol. 35:380-389.

24. Reddy, A. P. K., and Kauffman, H. E. 1973. Multiplication and movement of Xanthomonas oryzae in susceptible and resistant hosts. Plant Dis. Rep. 57:784-787.

25. Shan, L., He, P., Zhou, J. M., and Tang, X. 2000. A cluster of mutations disrupt the avirulence but not the virulence function of AvrPto. Mol. Plant-Microbe Interact. 13:592-598.

26. Shaner, G., and Finney, R. E. 1977. The effect of nitrogen fertilization on the expression of slow-mildewing resistance in knox wheat. Phytopathology 67:1051-1056.

27. Song, W., Wang, G., Chen, L., Kim, H., Pi, L., Holsten, T., Gardner, J., Wang, B., Zhai, W., Zhu, L., Fauquet, C., and Ronald, P. 1995. A receptor kinase-like protein encoded by the rice disease resistance gene, Xa21. Science 270:1804-1806.

28. Sun, W., Dunning, F. M., Pfund, C., Weingarten, R., and Bent, A. F. 2006. Within-species flagellin polymorphism in Xanthomonas campestris pv. campestris and its impact on elicitation of Arabidopsis FLAGELLIN SENSING2-dependent defenses. Plant Cell 18:764-779.

29. Sun, X., Cao, Y., Yang, Z., Xu, C., Li, X., Wang, S., and Zhang, Q. 2004. $X a 26$, a gene conferring resistance to Xanthomonas oryzae pv. oryzae in rice, encodes an LRR receptor kinase-like protein. Plant J. 37:517-527.

30. Swarup, S., De Feyter, R., Brlansky, R. H., and Gabriel, D. W. 1991. A pathogenicity locus from Xanthomonas citri enables starins from several pathovars of Xanthomonas campestris to elicit canker-like lesions on citrus. Phytopathology 81:802-809.
31. Tao, Y., Xie, Z., Chen, W., Glazebrook, J., Chang, H. S., Han, B., Zhu, T., Zou, G., and Katagiri, F. 2003. Quantitative nature of Arabidopsis responses during compatible and incompatible interactions with the bacterial pathogen Pseudomonas syringae. Plant Cell 15:317-330.

32. Tornero, P., and Dangl, J. L. 2001. A high-throughput method for quantifying growth of phytopathogenic bacteria in Arabidopsis thaliana. Plant J. 28:475-481.

33. Wang, G. L., Ruan, D. L., Song, W. Y., Sideris, S., Chen, L., Pi, L. Y. Zhang, S., Zhang, Z., Fauquet, C., Gaut, B. S., Whalen, M. C., and Ronald, P. C. 1998. Xa21D encodes a receptor-like molecule with a leucine-rich repeat domain that determines race-specific recognition and is subject to adaptive evolution. Plant Cell 10:765-779.

34. Yang, B., Sugio, A., and White, F. F. 2006. Os8N3 is a host susceptibility gene for bacterial blight of rice. Proc. Natl. Acad. Sci. USA 103:1050310508.

35. Yang, B., Zhu, W., Johnson, L. B., and White, F. F. 2000. The virulence factor AvrXa7 of Xanthomonas oryzae pv. oryzae is a type III secretion pathway-dependent nuclear-localized double-stranded DNA-binding protein. Proc. Natl. Acad. Sci. USA 97:9807-9812.

36. Yang, Y., and Gabriel, D. W. 1995. Intragenic recombination of a single plant pathogen gene provides a mechanism for the evolution of new host specificities. J. Bacteriol. 177:4963-4968.

37. Yoshimura, S., Yamanouchi, U., Katayose, Y., Toki, S., Wang, Z. X., Kono, I., Kurata, N., Yano, M., Iwata, N., and Sasaki, T. 1998. Expression of $\mathrm{Xal}$, a bacterial blight-resistance gene in rice, is induced by bacterial inoculation. Proc. Natl. Acad. Sci. USA 95:1663-1668.

38. Yoshimura, S., Yoshimura, A., Iwata, N., McCouch, S. R., Abenes, M. L., Baraoidan, M. R., Mew, T. W., and Nelson, R. J. 1995. Tagging and combining bacterial-blight resistance genes in rice using RAPD and RFLP markers. Mol. Breed. 1:375-387.

39. Zhu, W., Yang, B., Chittoor, J. M., Johnson, L. B., and White, F. F. 1998. AvrXa10 contains an acidic transcriptional activation domain in the functionally conserved C terminus. Mol. Plant-Microbe Interact. 11:824-832. 